\title{
Development of Corrugated Fiber Board Cartons for Long Distance Transport of Tomatoes in India
}

\author{
Girja Sharan \\ Centre for Management in Agriculture \\ Indian Institute of Management \\ Ahmedabad, India, 380015 \\ gsharan@iimahd.ernet.in \\ S. Srivastav \\ Department of Food Processing Technology \\ A. D. Patel Institute of Technology \\ New V V Nagar, Anand, India, 388121 \\ shivmurtis@gmail.com \\ Kishor P. Rawale \\ Assistant Manager \\ Jain Irrigation Systems Ltd \\ (Agriculture \& Food Division) \\ Sirsoli Road, Jalgaon, India, 425001 \\ kishor27@yahoo.com \\ Umang Dave \\ Core Emballage Limited \\ Core House, Off C. G. Road \\ Ahmedabad, India, 380006
}

Abstract - This paper contains an account of the development of corrugated fiber board (CFB) cartons for the transport of tomatoes for the growers of Gujarat, India and Himachal, India. Steps involved included (a) interaction with the growers in order to understand the problem associated with existing packaging (peti, a box made of strips of wood and the need for a substitute), (b) tests on peti under compression - drop and vibration testing to determine its strength and weakness for long truck journeys, (c) design of a new substitute, (boxes made of CFB) and testing of the prototypes in the laboratory and on actual road journeys, and (d) launch of the boxes in the market. The authors carried out the design, lab testing and field trials of the cartons in Gujarat and the launch of the cartons in the season of 2000. The developed cartons were implemented in Himachal with the launch taking place in the summer of 2001. Some undergraduate students of agricultural engineering were involved in the project as summer interns. Although technical papers based on this development were published elsewhere earlier, a comprehensive narrative detailing the context, the reasons for carrying out the work, and the steps involved was considered useful as it highlights the fact that some times important problems remain unsolved not because the engineering is difficult, but because the environment is such that the initiatives are lacking.

Index Terms - Packaging of tomatoes, fruit damage during transit, packaging for shipment. 


\section{INTRODUCTION}

Gujarat, a province in north-west India, produces about 700,000 tons of tomatoes each season. Growers are mostly small farmers. The crop is planted in August. Harvesting commences in November and continues through March. Growers pack the produce at the farmstead and then transport the tomatoes via trucks to the wholesale market in Ahmedabad city for auction. Growing areas lie in a $200 \mathrm{~km}$ radius around the city. Early in the harvesting cycle only a small quantity of produce arrives for auction. Arrivals peak toward the end of December and then a gradual decline sets in. Growers realize a better price early in the harvesting process. Prices decline considerably by the middle of the harvesting season. In some seasons, the decline is so steep that growers are unable to recover even the cost of packaging and transport. There are thousands of small growers and all are impacted severely by this price differential. The problem was noticed near about January 1998 when growers were forced to suspend picking mid-season due to a slump in prices. Media highlighted the problem. The small farms were visited and a customer needs assessment undertaken. The farmers indicated that when prices are low in Ahmedabad, higher prices actually prevail in adjoining provinces where during that time there is no local crop. The deterrent to marketing their tomatoes there was the lack of sturdy packaging which could safely transport the produce to such distant markets such as Bombay (500 km), Jaipur (700 km), Delhi (900 km), and Bangalore (2000 km). Their conventional packaging 'peti', a box made of strips of wood nailed together, would not adequately protect the produce during transit.

The information gathered from growers suggested that the damages incurred in transit with tomatoes packed in petis needed to be quantified. An investigation was therefore carried out to examine how well the peti protected the produce in transit. This was done in the month of January- February 1998 and marked the beginning of the work of design, tests and launch in two different areas that was carried out in subsequent three year period. Results from this preliminary investigation were published in the later part of that year (Siripurapu, Gabani and Sharan 1998). In the preliminary investigation, random samples of petis arriving at Ahmedabad auction market were emptied and fruit visually inspected for mechanical damages. Petis that had traveled $120 \mathrm{~km}$ had $3-4.5 \%$ (600 to $900 \mathrm{gm}$ in $20 \mathrm{~kg}$ ) fruit with serious damages - bursts, bruises, and/or fresh skin cracks. Those that had traveled $270 \mathrm{~km}$ had greater damages ranging from 5.5 to 7\%. Mechanical damages tend to grow non-linearly with transit distance. Thus the view of the growers about likely losses on longer journey was well-founded. It became apparent that better packaging would be needed to enable growers to send produce safely over longer distances.

The next step was to search for a better box in the market. There are a number of box makers in the region - including some large ones. Interaction indicated that some of the box makers were aware of the packaging problems of tomato growers but had no plans to address it. They said they did not have experience in the design of containers for materials that need special care and are perishable. They also felt that tomatoes, being a low value produce, might not permit the tomato growers to spend more for better packaging. This conclusion triggered the initiative reported here. Two boxes made of corrugated fiber board (CFB) were developed keeping in mind the physiological and rheological properties of tomatoes and the economic conditions of the growers. One box was launched in the Gujarat market during the 1999-2000 season, just over a year after the problem was identified. The second box was modified slightly in response to needs of growers of a different region (Himachal) who were also in search of 
better packaging. It was named Himachal Carton and launched in 2001 in that region. This paper describes the development of the Himachal Carton through the following stages.

1. Survey of packaging currently used and the engineering evaluation of the most commonly employed carton to identify its merits and demerits.

2. Setting specifications for new packaging in consultation with the stakeholders-growers, transporters, handlers and traders.

3. Design, prototyping, and laboratory testing and field trial of the new packaging.

4. Introduction in the market.

\section{Engineering Evaluation of Peti}

A survey revealed that growers used an assortment of boxes to pack tomatoes including used CFB boxes that previously packed cold drink bottles, medicine, cosmetics, biscuits, or household appliances. These were purchased from scrap dealers. Flutes of these single-journey boxes get flattened on first use, resulting in a reduction of the compressive strength. These tend to bulge easily. Usage demonstrated that growers were in need of a better packaging. A more common mode of packaging was the peti - a box measuring 42x30x28 cm, holding $20 \mathrm{~kg}$ of produce. As already stated, a preliminary examination of produce transported in petis had confirmed that significant damage occurred in transit and that longer the travel, higher the damages. Peti was selected for study and evaluation (Figure 1). This study focused on the engineering properties of peti as container.

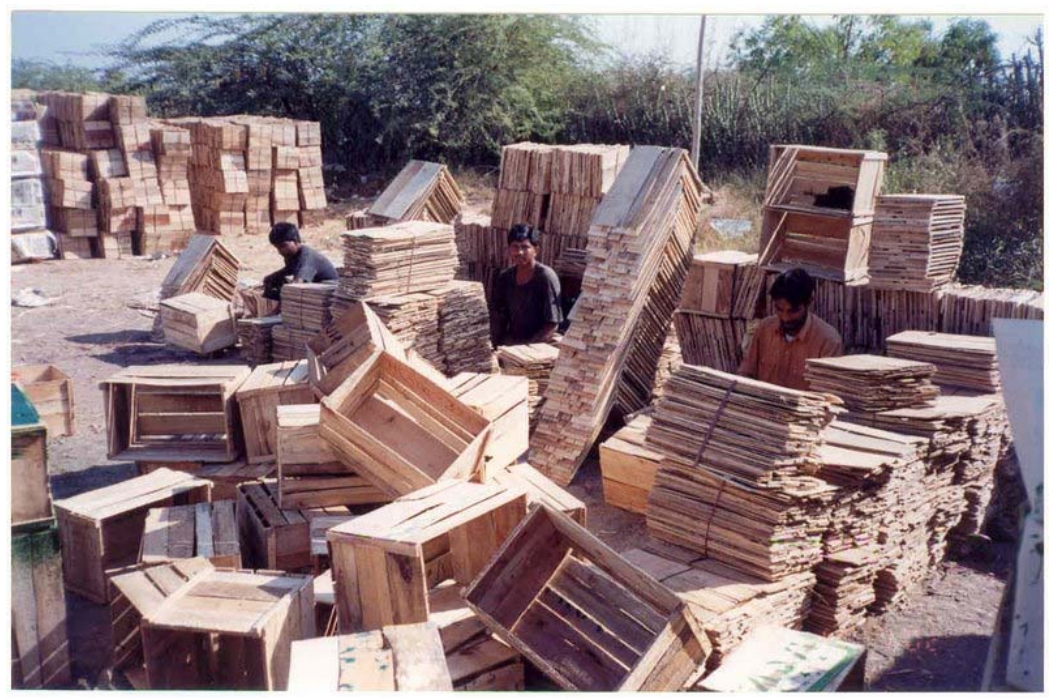

FIGURE 1

PETIS BEING ASSEMBLED

\section{MATERIALS AND METHODS}

Generally these boxes are stacked in columns of 4 to 6 in the truck. Thus, the bottom peti would have a load of about $125 \mathrm{~kg}$. On occasions there could be some extra loads such as person sitting atop. Petis are exposed to shocks while being loaded and unloaded. From farm gate to the retail stores there could be up to ten lift-drops. More severe shocks are encountered in transit when 
vehicle move on rough roads with potholes and speed bumps. Shocks induced from road surface are transmitted to the produce via wheel-suspension-packaging box link. A good box should preserve its structural integrity and protect the produce through all these. Three types of tests were carried out to evaluate the peti: a) Box Compression Test (BCT), b) Drop Test and c) Vibration Test.

For the BCT, empty petis were placed between platens of the machine (Unique Enterprises, Pune, India). As the upper platen moved down, deformation and load were displayed on the read-out panel. Loading rate was $11.8 \mathrm{~mm} /$ minute. Deformation was noted at intervals of $25 \mathrm{~kg}$. Six replications were made. Graphical results are discussed presently.

Drop tests involved subjecting petis filled with $20 \mathrm{~kg}$ tomato to a sequence of drops. Two types of test were done: a) straight drop from height of $20 \mathrm{~cm}$, and b) one edge of the box bottom remained on the platform, while the opposite edge was lifted to an angle of 25 degree and dropped. Structural damages to petis and to produce were noted.

Vibration tests were done on a machine supplied by the same manufacturer. It had pre-set frequency (3 Hz) and pre-set amplitude (15-mm horizontal and $6 \mathrm{~mm}$ vertical). The manufacturer indicated that one hour on the machine represented $1000 \mathrm{~km}$ of road travel. Three identical tomato-filled boxes were placed side by side on the platform of a vibrator. The machine was turned on. One box was removed after every 20 minutes. At the end of the test, damages to the boxes and produce were noted.

Engineering tests on the peti were conducted in July 1998. Note the preliminary investigation mentioned earlier aimed at examining the state of the fruits packed in petis on arrival at the market for auction. This investigation did not put petis to any test. Engineering tests being described now aimed at finding out the strength and weaknesses of the peti as packaging box. Therefore, a set of newly made petis was procured from the vendors for test. The outer dimension of the sample petis was $42 \times 30 \times 28 \mathrm{~cm}$, tare weight between 2.4 to $2.6 \mathrm{~kg}$. Petis were stored for 72 hours in a room with temperature at $23^{\circ} \mathrm{C}$ and the relative humidity of 50 percent. Tests were carried out in the laboratory of Core Emballage Limited, Ahmedabad, a large box maker in India. This testing was undertaken during the non-growing season in Gujarat; therefore tomatoes were purchased from the wholesale market each day in the morning. Fruits used for tests were carefully selected to ensure that they were free from cracks and skin discontinuities. Tomatoes were also sorted for size uniformity with a template with various sizes of openings. Fruits of 50-55 mm along major axis were selected for tests.

Test results, that is the behavior of peti under BCT, drop and vibration, were published earlier (Sharan et al, 1999a, 1999b, Sharan and Srivastav, 2000). Some key results are given here. Deformation of petis increased (Figure 2) almost linearly with load. It did not exceed $6 \mathrm{~mm}$ under a load of $250 \mathrm{~kg}$. Fresh produce carrying boxes are required not to deform more than 10 mm when stacked in columns in a truck (Technical Association of the Pulp and Paper Industry, 1993). Peti met that requirement. Up to five straight drops did not cause significant damage to peti or to produce. After the fifth drop, (Table I) the nails of the corner joints loosened causing the box to deform diagonally. Fruit that burst or developed skin discontinuity were $4 \%$ after six straight drops and 7\% after twelve straight drops. Angular drops are nearly equally severe. Peti 
was not strong enough to withstand long enough sequences of drops normally expected in handling. A significant proportion of the produce, especially near the bottom, suffered damages.

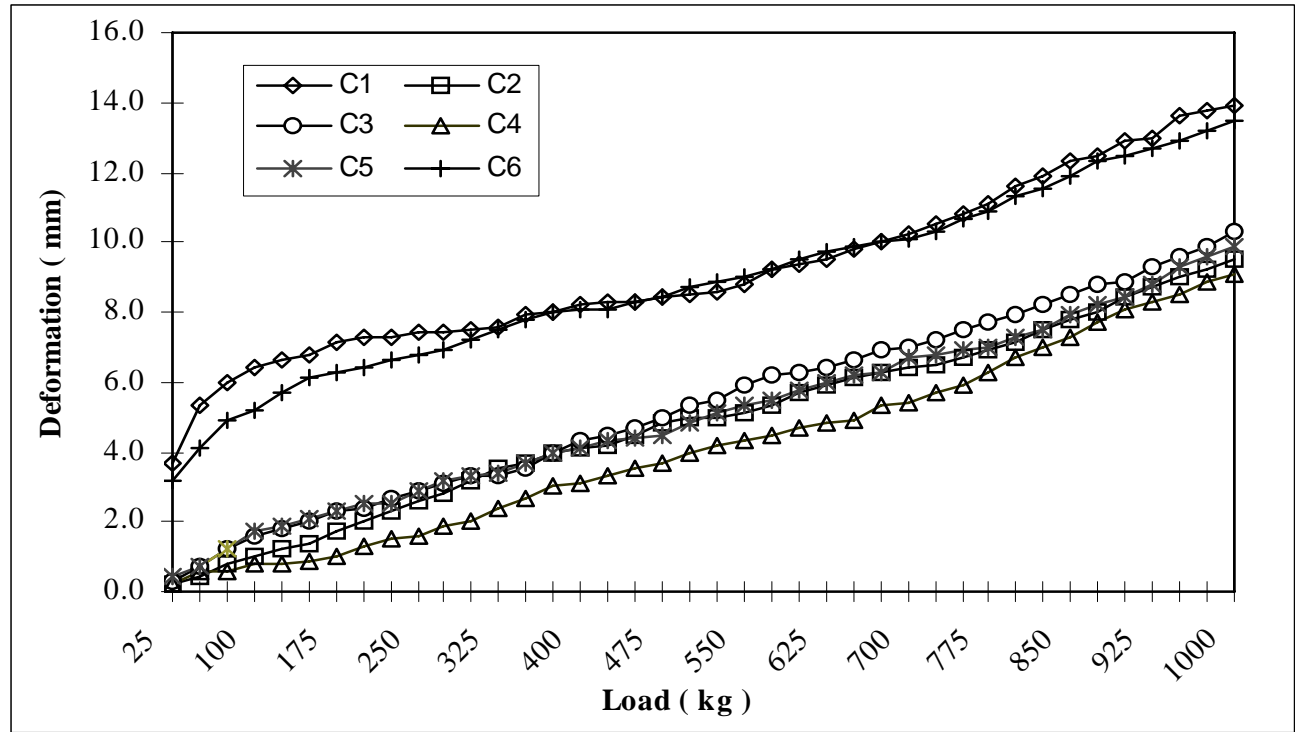

FIGURE 2

FORCE DEFORMATION CURVE OF PETI

Vibration tests simulated road travel. The acceleration to which the boxes under test were subjected to is described (Technical Association of the Pulp and Paper Industry, 1993) by equation (1). Given the frequency and amplitude of this particular machine, the acceleration to which the boxes were subjected to worked out to $0.6 \mathrm{~g}$ units.

$$
G=\frac{D f^{2}}{250}(1)
$$

\section{Where}

$$
\begin{aligned}
& G=\text { Number of } g \text { units } \\
& D=\text { Displacement }, \mathrm{mm} \\
& f=\text { Frequency }, \mathrm{Hz}
\end{aligned}
$$


TABLE I

DAMAGE TO PETI AND PRODUCE IN DROP TESTS

\begin{tabular}{|c|c|c|c|}
\hline $\begin{array}{l}\text { Weight of peti filled } \\
\text { with tomato } \\
\text { ( kg) }\end{array}$ & $\begin{array}{l}\text { Drops type } \\
\text { and number }\end{array}$ & Damage to peti & Damage to tomato \\
\hline 20 & 6 ( straight) & $\begin{array}{l}\text { Nails loosened, cracks } \\
\text { on some slats diagonal } \\
\text { elongation } 0.9-1.4 \mathrm{~cm}\end{array}$ & $\begin{array}{c}\text { Fruits in the lower part } \\
\text { bust, burst fruit in three } \\
\text { replications } 734 \text { gm } \\
\text { (4\% of total) }\end{array}$ \\
\hline 20 & 12 ( straight) & $\begin{array}{l}\text { Nails loosened, cracks } \\
\text { on some slats diagonal } \\
\text { elongation } 0.4-0.9 \mathrm{~cm}\end{array}$ & $\begin{array}{l}\text { Fruits in the lower part } \\
\text { bust , burst fruit } 1280 \\
\text { gm ( } 7 \% \text { of total) }\end{array}$ \\
\hline 20 & 10 (angular) & $\begin{array}{l}\text { One side of the cartoon } \\
\text { was totally damaged, } \\
\text { nails come out } \\
\text { diagonal elongation } \\
1.4 \mathrm{~cm}\end{array}$ & $\begin{array}{l}\text { Fruits in the lower part } \\
\text { bust , burst fruit } 850 \\
\text { gm ( } 4.6 \% \text { of total) }\end{array}$ \\
\hline
\end{tabular}

Results of vibration testing are given in Table II. Vibrations loosen the corner joints much the same way as in the course of drops. The amount of damaged produce increases with the duration of exposure to vibration. It was concluded that peti was strong in compression but not strong enough to withstand shocks encountered in handling and transit. Its corner joints loosen causing diagonal deformation. Fruits in the lower part are damaged. An alternative that could transport the produce safely over longer distance was considered desirable.

TABLE II DAMAGES TO PRODUCE AND PETI IN VIBRATION

\begin{tabular}{ccc}
\hline $\begin{array}{c}\text { Exposure time } \\
(\mathrm{min})\end{array}$ & $\begin{array}{c}\text { Proportion of produce damaged } \\
(\%)\end{array}$ & $\begin{array}{c}\text { Diagonal } \\
\text { Elongation of peti } \\
(\mathrm{cm})\end{array}$ \\
\hline 20 & 7.0 & 0.3 \\
40 & 10.5 & $0.4-0.6$ \\
60 & 13.5 & $1-1.5$ \\
\hline
\end{tabular}

\section{Specifications of New Packaging Box}

Desired features of new boxes were developed by consultation with the growers, the loaders in the wholesale market who do the loading and unloading, traders who carry out auction on behalf of the growers, officers of the wholesale market who have interest in improvement in the packaging and handling of produce, truckers who transport the produce from farm to market on behalf of the growers. Consultations were done by talking to participants in each of the groups without the use of any structured format. The number of growers consulted was larger about fifty while others were fewer - about a dozen each. There was a general consensus that packaging needs to be improved. Growers of Gujarat expressed the view that subsidies be given to enable them to buy batter boxes when ready. The design team felt that this was not in their control, but 
that the effort will be to create boxes that are affordable . Request for subsidy was not made by growers of the northern hill region who grew off-season tomatoes and realized better prices in general. Other specifications generated through group discussions are listed.

(a) Stacking strength - $250 \mathrm{~kg}$ - so that these could be stacked to height of up to $2 \mathrm{~m}$ common in Indian trucks.

(b) Withstand handling abuse - retain structural integrity through a sequence of at least 15 straight and angular drops.

(c) Withstand road-induced shock - protect produce and its own structural integrity over a $2000 \mathrm{~km}$ road journey.

(d) Ventilation - 8 holes of $20 \mathrm{~mm}$ diameter.

(e) Capacity - 20 to $25 \mathrm{~kg}$ of tomatoes.

(f) Material and Environmental Factor - material used should not create disposal problems.

(g) Cost -about Rs.15 per piece comparable to that of the peti.

(h) Ease of Handling - provision of grip for handling.

(i) Produce Identification - graphics printable

Two different boxes VC-20, VC-15 were (Figure 3) designed with specifications given in Table III.

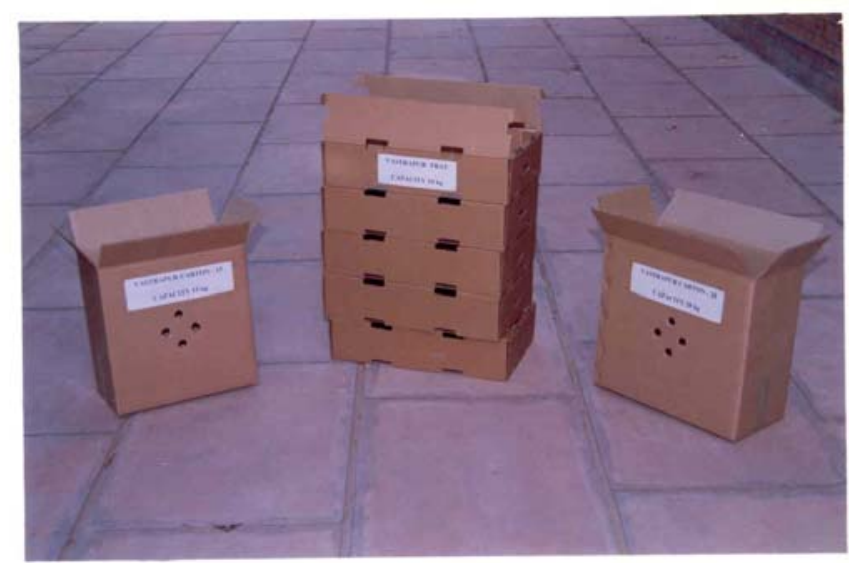

FIGURE 3

BOX VC-20 (LEFT), VC-15 (RIGHT) 
TABLE III

SPECIFICATIONS

\begin{tabular}{lcc}
\hline \multicolumn{1}{c}{ Specifications } & VC-20 & $V C-15$ \\
\hline Capacity $(\mathrm{kg})$ & 20 & 15 \\
Material of construction & CFB, 5 ply & CFB, 5 ply \\
Internal dimensions (mm) & $430 \times 205 \times 390$ & $363 \times 192 \times 373$ \\
Style of box & RSC 0201 & RSC 0201 \\
Direction of flutes & Vertical & Vertical \\
Type of flutes & B/C & B/C \\
Grammage of plies $\left(\mathrm{g} / \mathrm{m}^{2}\right)$ & 150 & 150 \\
Bursting strength $\left(\mathrm{kg} \cdot \mathrm{cm}^{2}\right)$ & $11 \pm 1$ & $11 \pm 1$ \\
Cobb value $\left(\mathrm{g} / \mathrm{m}^{2}\right)$ & 140 gsm & 140 gsm \\
Type of adhesive & Starch based & Starch based \\
Number of pieces per box & 1 & 1 \\
Joints & Glued & Glued \\
Number of ventilation holes & 8 & 8 \\
Diameter and position of holes & 24.5 mm, long wall & 24.5 mm, long wall \\
\hline
\end{tabular}

\section{Laboratory and field trial}

Fifty of each box (VC-20 and VC-15) were fabricated and tested in the manner described above. These tests were of the newly developed prototypes of the boxes, similar to those carried out on the petis and described earlier. All cartons used in the test were pre-conditioned for 72 hours in a room where relative humidity was maintained at 50 per cent and a temperature of $23^{\circ} \mathrm{C}$ was maintained (Sharan, et al, 1999b). Tomatoes (trade name Rashmi) were commercial hybrids. BCT tests (Table IV) confirmed that both boxes were capable of withstanding $250 \mathrm{~kg}$ load with less than $6 \mathrm{~mm}$ deformation. As expected, the damage increased with the increase in the number of drops (Table V). There was no damage to the boxes during the drops in either the straight or angular drop tests. Vibration tests revealed that damage to produce increased with exposure time (Table VI). Box VC -15 retained its structural integrity. VC-20 failed after 35-55 minutes. Table VII gives a summary of attributes of wood and newly developed boxes. 
TABLE IV

BCT TEST DATA

\begin{tabular}{ccc}
\multirow{2}{*}{ Load $(\mathrm{kg})$} & \multicolumn{2}{c}{ Deformation $(\mathrm{mm})$} \\
\cline { 2 - 3 } 25 & $V C-15$ & $V C-20$ \\
50 & 0 & 0 \\
75 & 0 & 0 \\
100 & 1.9 & 1 \\
125 & 3.1 & 2.1 \\
150 & 3.8 & 2.8 \\
175 & 4.1 & 3.4 \\
200 & 4.6 & 3.7 \\
225 & 5.1 & 4.3 \\
250 & 5.6 & 4.9 \\
275 & 5.7 & 5.4 \\
300 & Failure & 5.9 \\
325 & & 6.5 \\
350 & & 6.6 \\
25 & & Failure
\end{tabular}

VC-15 : Values up to $225 \mathrm{~kg}$ are mean of 6, and $250 \mathrm{~kg}$ value of 4 replications

VC-20 : Values up to $300 \mathrm{~kg}$ are mean of 5 , and $320 \mathrm{~kg}$ value of 4 replications

TABLE V

DAMAGE TO PRODUCE IN DROP TEST

\begin{tabular}{ccccc} 
& \multicolumn{3}{c}{ Straight Drop $(20 \mathrm{~cm})$} & Angular Drop $\left(25^{0}\right)$ \\
\cline { 2 - 5 } Cartons & 6 nos. & 12 nos. & 15 nos. & 15 \\
VC-15 & $2.1 \%$ & $2.8 \%$ & $3.2 \%$ & $2.9 \%$ \\
VC-20 & $2.6 \%$ & $3.3 \%$ & $4.0 \%$ & $2.3 \%$
\end{tabular}

Damage values mean of 3 replications

TABLE VI

DAMAGE TO PRODUCE IN VIBRATION TEST

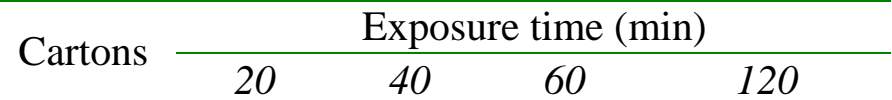

VC-15 $3.6 \% \quad 5.3 \% \quad 6.2 \% \quad-$

VC-20 $3.2 \% \quad 5.4 \% \quad-\quad \quad-$

Damage is mean of 2 replications and rounded off. 
TABLE VII

COMPARATIVE PERFORMANCE OF PETI AND CARTONS

\begin{tabular}{|c|c|c|c|}
\hline Particulars & Peti & $\begin{array}{c}\text { VC-15 } \\
\text { (15 kg cap) }\end{array}$ & $\begin{array}{c}\text { VC-20 } \\
\text { (20 kg cap) }\end{array}$ \\
\hline \multicolumn{4}{|l|}{ Compression Test } \\
\hline (a) Stacking strength & $>>350 \mathrm{~kg}$ & $250 \mathrm{~kg}$ & $325 \mathrm{~kg}$ \\
\hline (b) Compressive strength & $43 \mathrm{~kg} / \mathrm{mm}$ & $35 \mathrm{~kg} / \mathrm{mm}$ & $42 \mathrm{~kg} / \mathrm{mm}$ \\
\hline \multicolumn{4}{|l|}{ Vibration Test } \\
\hline \multicolumn{4}{|l|}{ Damage to tomato after } \\
\hline (a) 20 minutes & $7.0 \%$ & $3.6 \%$ & $3.2 \%$ \\
\hline (b) 40 minutes & $10.5 \%$ & $5.3 \%$ & $5.4 \%$ \\
\hline (c) 60 minutes & $13.5 \%$ & $6.2 \%$ & - \\
\hline (d) 120 minutes & - & - & - \\
\hline \multicolumn{4}{|l|}{ Drop Test } \\
\hline \multicolumn{4}{|l|}{$\begin{array}{l}\text { Damage to tomato after } \\
\text { (i) Straight fall }(20 \mathrm{~cm})\end{array}$} \\
\hline (a) 6 drops & $4.0 \%$ & $2.1 \%$ & $2.6 \%$ \\
\hline (b) 12 drops & $6.0 \%$ & $2.8 \%$ & $3.3 \%$ \\
\hline \multicolumn{4}{|l|}{ (ii) Angular fall ( $25^{0}$ tilt $)$} \\
\hline (a) 10 drops & $4.0 \%$ & - & - \\
\hline (b) 15 drops & - & $2.9 \%$ & $2.3 \%$ \\
\hline Jan-Feb, 1999 & Core Emballaq & Ltd, Ahmedabad & \\
\hline
\end{tabular}

After laboratory testing, a transport trial was carried out. One-half of a truck was loaded with tomatoes packed in petis and the other half with produce packed in VC-15 and VC-20. Overall tomato damage in petis was found to be higher (4.6 per cent) than that on Vastrapur cartons (2.8 per cent) (Sharan et al, 1999b, Sharan and Srivastav, 2000). The boxes appeared to be satisfactory in performance and an improvement over the petis.

The box (VC-20) was introduced in the Gujarat region in the season of 1999-2000. About a year after the launch of cartons in Gujarat region, the International Development Enterprises (IDE, India), an NGO working with small tomato growers in the hills in Himachal, expressed interest in the boxes. There too the growers used similar peti. But the Himachal government had just passed a law banning felling trees which might have been used to make the petis. Pine trees were mostly used. IDE perceived that an alternative would need to be developed urgently. The IDE team visited us to see the box, took a sample to show to the growers in Solan area, and selected VC-15 for trial. They also invited us to visit their growers to receive feedback and to determine if any special features were needed. We visited the area and had discussions with the growers. The post harvest practices were documented. Almost all aspects were similar here except one - rain occurs during the harvest season at this location and therefore the cartons will need protection. A positive aspect was that the tomatoes here were off-season and attracted much better prices making it easier to spend some more for packaging. 
Kits consisted of sets of wood strips cut to measure. Suppliers delivered the kits at a convenient pick-up point on the road side near the farms. Growers needed only to use hammer and nails to assemble the peti from the kits. It took about four minutes to assemble one. Peti had provision for aeration and a smooth inner finish, though nails some times protruded. Tare weight of freshly made peti was $2.7 \mathrm{~kg}$. Petis were usually available for Rs. $18-20$ per piece. Growers indicated that they liked the $\mathrm{VC}-15$ box. But before finalizing the choice they required that a transport trial be organized from their area to Delhi. Two thousand five hundred boxes were manufactured and taken to Solan. They set the aims of trial as follows: Overall damage to the produce was $1.5 \%$ in VC, nearly half of that in the $(2.1 \%)$ in the petis (Sharan and Rawale, 2001). Growers who witnessed the trial also suggested modifications relating to the capacity of the box, placement of ventilation holes, side grip, moisture resistance and competitiveness in pricing. The results of the transport trial were subsequently published (Sharan and Rawale 2001). The modifications were carried out and the new box-Himachal Carton - was made available to a firm in Delhi to produce and market the new product. Boxes began to be accepted gradually. By early 2002, the producers (tomato growers) had an agreement with a manufacturer based in Delhi (Perfect Packaging) to produce 100,000 cartons (Phansalkar 2003). The market was not tracked, but visits to the wholesale market were made independently on subsequent several occasions to obtain feedback. Large stacks of produce in the new boxes were observed. They were easy to spot (red color) and carried graphics that was agreed upon at the transfer of the technology (Figures 4 and 5) and Shimla area. We continue to get information (though we do not track it now) on its increased usage.

The use of new packaging benefited the growers as they attracted a better price for the produce in auction. This began to happen after the traders noted that the extent of damage in the produce was less in these boxes than in petis. The box manufacturers gained a new market with large potential for their product. The society benefited due to the fact that use of wood was reduced and with that the pressure on the forests in the hills. This latter effect is important though it was not the reason that drove the effort.

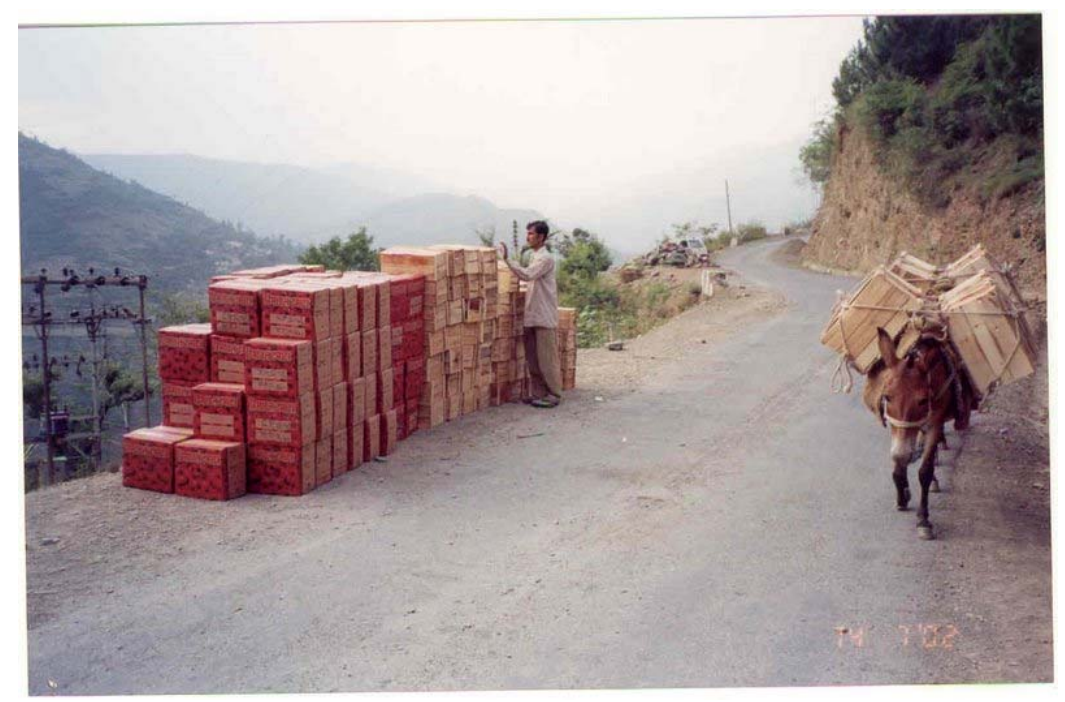

FIGURE 4

HIMACHAL CARTONS AT ROADHEAD FOR TRANSPORT 


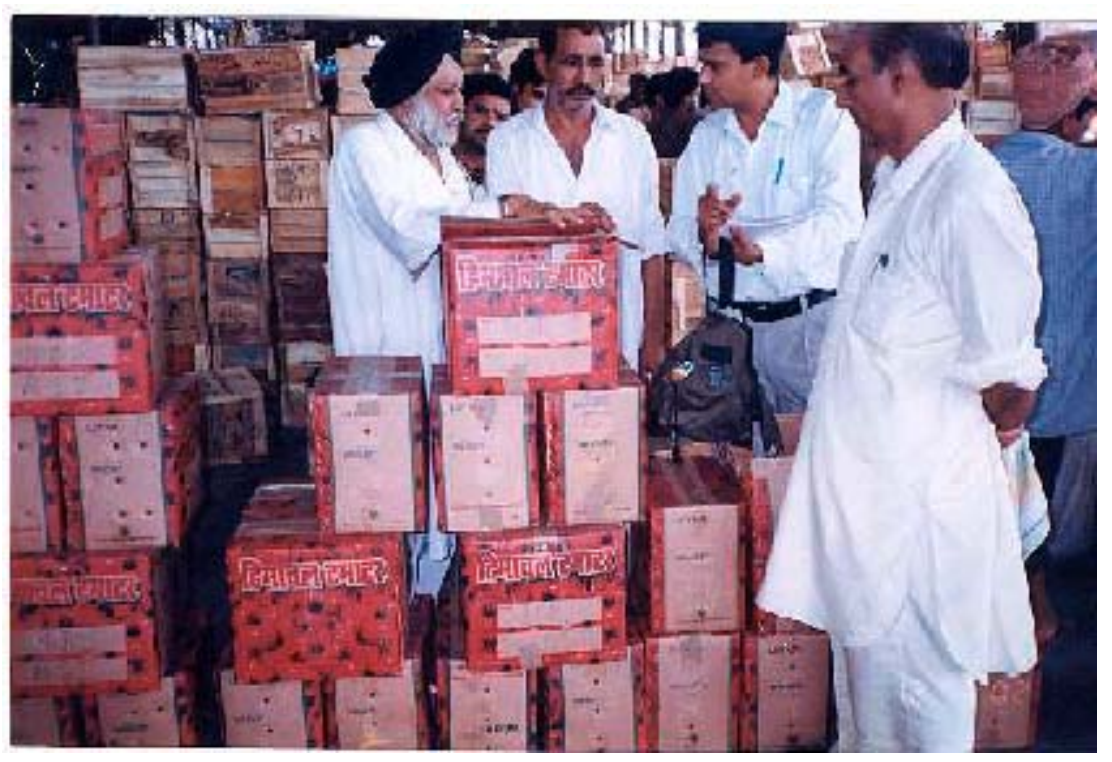

FIGURE 5

HIMACHAL CARTONS AT DELHI AUCTION MARKET

\section{CONCLUSION}

The wood box traditionally used by commercial growers to transport tomatoes to auction market in Gujarat province (India) was a poor packaging. It had sufficient compressive strength for fourtier stacking, typical loading arrangements on trucks, but could not withstand long sequences of lift-drops in handling and the dynamic shocks encountered in transit over rough roads. That constrained the growers to sell produce in Ahmedabad and deterred them from sending it to more distant markets to realize better prices. The grower's community consists of thousands of small farmers who could not engage R\&D institutions to solve their packaging problem. The local box makers too ignored the problem supposing that the growers would not be willing to pay for better packaging. The task of developing a safer and affordable packaging was recognized as important and was carried out in partnership with a large box maker. Two boxes were designed, fabricated, tested in the laboratory and also on actual road journey on truck. One of these two VC-20, was preferred by the growers of Gujarat who have the tradition of packing $20 \mathrm{~kg}$. The other, VC-15, was preferred by growers of Himachal who packed $15 \mathrm{~kg}$. Made of corrugated fiber board, the boxes are light weight, and easy to transport as flats in bulk to the growers' farms. Laboratory tests and actual road journey tests have shown that the new boxes protect the produce much better against hazards encountered in transit, in transfers from and to the truck, and within the market. Manufacturing arrangements were worked out with private firms and cartons introduced in the regional markets. The new boxes have gradually gained acceptance are in increasing use. 


\section{ACKNOWLEDGMENT}

Core Emballage Ltd., Ahmedabad for facilities of design studio and testing laboratory; Centre for Management in Agriculture, Indian Institute of Management, Ahmedabad for facilities; Ministry of Agriculture, Government of India, New Delhi for funding support; Growers from village Khanderaopura for cooperation in field trial of cartons; The Sardar Patel Wholesale Vegetable Market, Ahmedabad for cooperation in trials and for providing contacts with traders and growers.

\section{REFERENCES}

Phansalkar, S J (2003). "Evolving Technology through Collaboration and Partnership: the Case of the International Deveopment Enterprises (Inda)'s Work withTomato Packaging in Himachal Pradesh, India” pp. 32-44, in Hall, A J (et al) Post-harvest Innovations in Innovation: Reflections on Partnership and Learning. CPHP, South Asia.

Sharan G, Srivastav S., Monika K. (1999). "Mechanical Properties of Wood Carton Used for Long Distance Transport of Tomatoes”. Packaging India. Vol. 31(5). PP 7-15.

Sharan G, Dave U, Srivastava S, Sreenivas P. (1999). "Performance of Vastrapur Carton in Laboratory”. Packaging India. Vol. 32(2). PP 39-44.

Sharan G, Srivastav S. (2000). “Cartons for Farm Fresh Tomatoes”. Packaging India. Vol. 33(3). PP 37-41.

Sharan G. and Rawale K. (2001). "New Packaging Options for transporting tomatoes in India." Food Chain (International Journal of Small Scale Food Processing), No.29, November.

Siripurapu S. C. B., Gabani S. H., Sharan G. (1998). "Quality Evaluation of Tomatoes Arriving at Sardar Patel Market Ahmedabad: A Case Study”. Journal of Agricultural Engineering, 35(4):13-21, October-December 1998.

Technical Association of the Pulp and Paper Industry. (1993). "Standard Tests for Drop, Vibration and Compression Test”. Annual Book, Atlanta. 